\title{
Asymmetric Catalysis of the Carbonyl-Amine Condensation: Ki- netic Resolution of Primary Amines
}

\author{
Sayantani Das, Nilanjana Majumdar, Chandra Kanta De, Dipti Sankar Kundu, Arno Döhring, Anika Garczynski, \\ and Benjamin List* \\ Max-Planck-Institut für Kohlenforschung, Kaiser-Wilhelm-Platz 1, 45470 Mülheim an der Ruhr, Germany
}

\begin{abstract}
A Brønsted acid catalyzed kinetic resolution of primary amines is described that is based on the condensation between an amine and a carbonyl compound. 1,3Diketones react with racemic $\alpha$-branched amines to furnish the corresponding enantioenriched enaminone and recovered starting material. Good to excellent enantioselectivity was observed with both aromatic and aliphatic primary amines. This process represents the first small-molecule catalyzed kinetic resolution of aliphatic amines.
\end{abstract}

The condensation of an amine with a carbonyl compound is a fundamental organic reaction by itself, ${ }^{1}$ but also key to enzymatic and organocatalytic cycles, ${ }^{2}$ and to several important transformations including the Mannich, Petasis, Strecker, Pictet-Spengler, Paal-Knorr, Rodionov, and Kabachnik-Fields reactions. ${ }^{3}$ Despite its significance and utility in chemical synthesis however, a catalytic enantioselective variation of this reaction is unknown. Since the carbonyl-amine condensation is readily catalyzed by acids, we reasoned that an asymmetric version should be realizable using a chiral Brønsted acid catalyst. Such a process could be of significant utility in asymmetric synthesis and we became particularly intrigued by the idea to utilize it as a new approach for the kinetic resolution $(K R)$ of racemic primary amines (eq. 1).

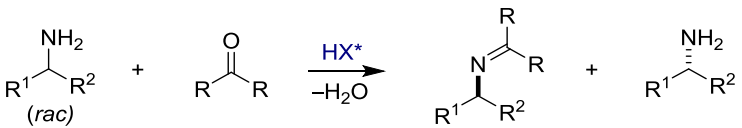

concept: kinetic resolution via acid catalyzed carbonyl-amine condensation

We now report the realization of this general concept with the design and development of a highly enantioselective condensation of a 1,3-diketone with racemic primary amines to the corresponding enantioenriched enaminone via KR.

Enzymatic KRs of chiral amines are well advanced and technically utilized. ${ }^{4}$ A particularly fascinating approach has been developed by Bäckvall et. al, involving the dynamic $\mathrm{KR}$ of rac-amines using a ruthenium-based racemization catalyst in combination with a lipase. ${ }^{5}$ In contrast, the KR of amines via small molecule catalysis is only emerging in recent years. ${ }^{6,7,8}$ Pioneering contributions to this field came from Fu et al. using a ferrocene based chiral DMAP catalyst and an azlactone carbonate as acylating reagent. ${ }^{6 a}$ Later, Seidel et al. reported a dual catalyst system consisting of chiral thiourea catalyst and DMAP, ${ }^{6 f}$ and Bode et al. resolved cyclic amines using an N-heterocyclic carbene catalyst in combination with a chiral hydroxamic acid cocatalyst. $^{6 i}$ Despite these advances, there is still no general organocatalytic approach available that is applicable to a broad range of chiral amines. In particular purely aliphatic amines could not previously been resolved in organocatalytic asymmetric kinetic resolutions.

An inherent problem of small-molecule-based amine acylation catalysis is the high nucleophilicity of amines, which can lead to non-enantioselective background catalysis. We initially wondered if a Brønsted acid catalyzed imine formation could be used to address this problem. However, the reversibility of the reaction and the potential for transimination may yet lead to other new problems. We realized that an appropriate choice of the carbonyl compound was crucial in the design of such process and specifically hoped that 1,3-diketones may be of utility, as they would lead to relatively stable enaminones, making the process much less reversible. Alternatively, 1,4-diketones may be used and lead to the corresponding pyrroles. ${ }^{9}$

Indeed, we commenced our studies by reacting racemic amine $\mathbf{1 a}$ with 1,3-diketone $\mathbf{2} \mathbf{a}$ in diethyl ether using $(S)$ TRIP (3a) as catalyst at $-5^{\circ} \mathrm{C}$ and obtained the corresponding enaminone 4 (Table 1). ${ }^{10}$ At $57 \%$ conversion, a low sfactor of 2.3 was achieved (entry 1). To improve the selectivity, $\beta$-ketoester $\mathbf{2 b}$ and 1,3-diketones $\mathbf{2 c}$ and $\mathbf{2 d}$ were tested (entries 2-4) and of those, the best selectivity ( $s=$ 5.2) was observed with branched diketone $2 c$ (entry 3 ). Towards identifying an improved catalyst, a systematic study exploring its $\mathrm{R}^{3}$-position was undertaken (entries 57). When $R^{3}$ is hydrogen (3b), the selectivity was lower than that of (S)-TRIP (3a) (entry 5), which led us to speculate that perhaps a more bulky group at this position may improve the enantioselectivity. ${ }^{11}$ Gratifyingly, an additional 
Table 1. Reaction Development ${ }^{\mathrm{a}}$

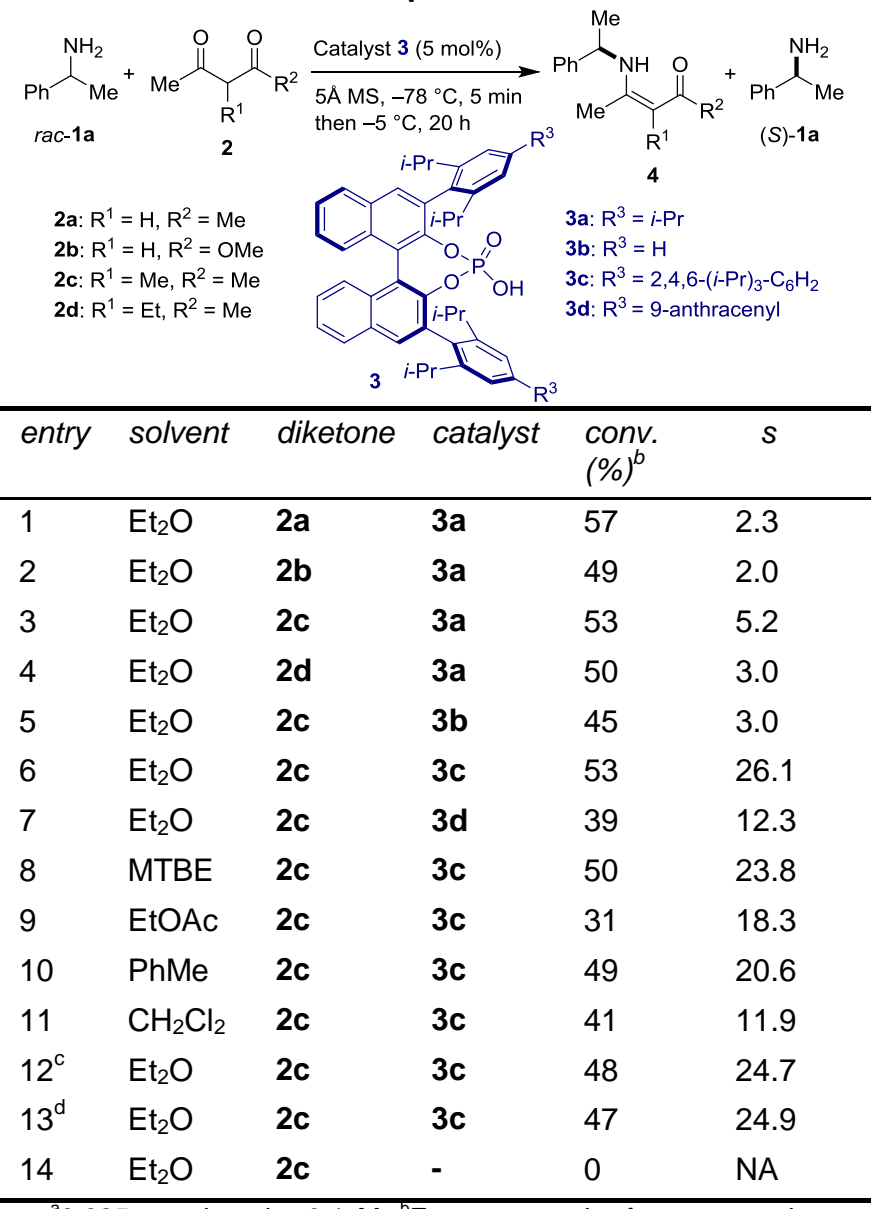

${ }^{a} 0.025 \mathrm{mmol}$ scale, $0.1 \mathrm{M} .{ }^{\mathrm{b}} \mathrm{Er}$, conv., and s-factor were determined by HPLC. ${ }^{9} 0.125 \mathrm{M}$. ${ }^{\mathrm{d}} 0.075 \mathrm{M}$. MTBE = methyl tert-butyl ether.

icantly increased the s-factor from 5.2 to 26.1 (entry 6). Modification of $R^{3}$ to 9 -anthracenyl in catalyst $\mathbf{3} \mathbf{d}$ gave lower conversion and selectivity than that displayed by catalyst $3 \mathrm{c}$ (entry 7). Accordingly, catalyst $3 \mathrm{c}$ was chosen in the following studies. The evaluation of different solvents (entries 811) showed that diethyl ether gave the best selectivity factor to resolve our model primary amine. The reaction was also performed at higher and lower concentrations (entries 1213) with little to no effect on selectivity and conversion. Finally, in the absence of a catalyst, no conversion to product was obtained (entry 14).

The scope of the reaction was next explored using the optimized reaction conditions (Chart 1). ${ }^{12} \mathrm{~A}$ broad range of rac-benzylic amines could be resolved. Irrespective of their electronics and sterics, and with different substituents at different ring positions, high selectivity factors were obtained (1a-1f). Excitingly, even aliphatic primary amines can be resolved with our method, displaying good to excellent selectivity $(\mathbf{1 g}-\mathbf{1 l})$. To the best of our knowledge, this is the first example of a small molecule-catalyzed kinetic resoIution of aliphatic primary amines. Remarkably, the catalyst can even enantiodifferentiate between an $n$ - $\mathrm{Pr}$ and a $\mathrm{Me}$ group in aliphatic amine 1j. Unfortunately, cyclic amines $\mathbf{1 m}$ and $1 \mathrm{n}$ did not furnish the desired product, even at elevated temperature. Furthermore, amino acid 10 also did not provide the corresponding enaminone.
We also conducted a single flask competition experiment in which 0.5 equivalents of rac-aromatic amine $\mathbf{1 a}$ and 0.5 equivalents of rac-aliphatic amine $\mathbf{1 g}$ were subjected to our reaction conditions. Interestingly, the two different amines were independently resolved, each with good selectivity (eq. 2). Further, to demonstrate the practicability of our method, a gram scale experiment was performed (eq. 3). The reaction of one gram of amine $\mathbf{1 g}$ in the presence of only 1 mol\% of catalyst 3c (which was recovered from our scope studies shown in Chart 1) proceeded smoothly with an Sfactor of $\mathbf{4 6}$ and gave at $51 \%$ conversion $(S)$ - product $(R)-\mathbf{4 g}$ in $41 \%$ yield and $94: 6$ er. The recovered amine $1 \mathrm{~g}$ was isolated as benzamide derivative $\mathbf{5 g}$ in $46 \%$ isolated yield with an er of 95:5. Finally, removal of the enone moiety was readily accomplished and enaminone $\mathbf{4 g}$, upon treatment with hydroxylamine hydrochloride, was fully converted into free amine $\mathbf{1 g}$ with preservation of enantiopurity (eq. 4). ${ }^{9}$ Our method therefore provides access to both amine enantiomers.
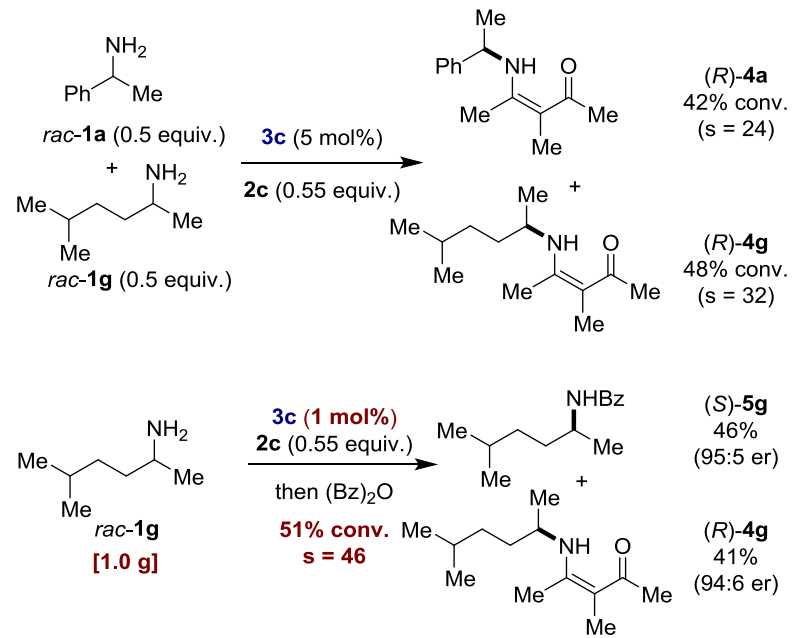<smiles>CC(=O)C(C)=C(C)NC(C)CCC(C)C</smiles>
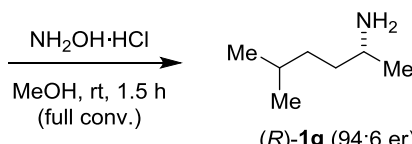

$(R)-19(94: 6$ er)
In summary, we have developed a Brønsted acid catalyzed kinetic resolution of primary amines that is based on their condensation with a diketone. This reaction is a proof-ofprinciple for the general concept of catalyzing aminecarbonyl condensations enantioselectively, a concept which we assume to be widely applicable to many other transformations. Our methodology tolerates a wide variety of amines, and most remarkably, even aliphatic amines are resolved with good to excellent selectivity. Currently, we can only speculate on the origin of enantioselectivity of our reaction. In principle, any of the multiple steps of the condensation reaction, or combinations thereof, could govern the high selectivity. Even an enantiomer differentiating interaction of the catalyst with the amine enantiomers cannot be excluded at this point. Mechanistic studies and an expansion of the scope of our methodology are of high current interest in our laboratory. 
Chart 1. Scope of the Kinetic Resolution of rac-Amines: ${ }^{a}$

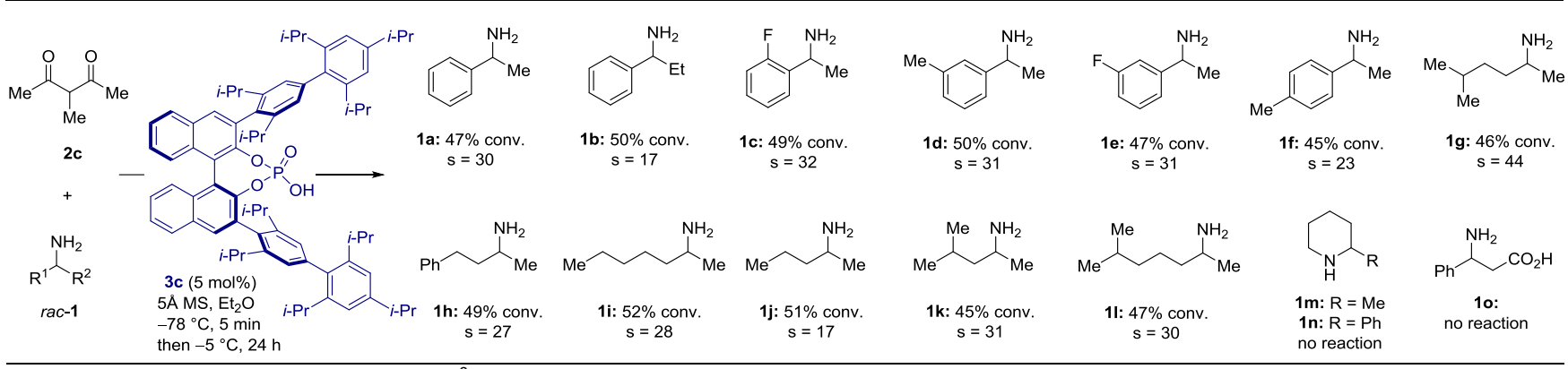

${ }^{a} 0.1 \mathrm{mmol}$ scale. er determined by HPLC. ${ }^{9}$

\section{ASSOCIATED CONTENT}

\section{Supporting Information}

Experimental procedures, characterizations and analytical data of products, and spectra of NMR and HPLC. This material is available free of charge via the Internet at http://pubs.acs.org.

\section{AUTHOR INFORMATION}

\section{Corresponding Author}

*list@kofo.mpg.de

\section{Notes}

The authors declare no competing financial interest.

\section{ACKNOWLEDGMENT}

Generous support by the Max-Planck-Society and the European Research Council (Advanced Grant "CHAOS") is gratefully acknowledged. We thank the members of our NMR, MS, HPLC and X-ray crystallography departments for their excellent service.

\section{REFERENCES}

(1) (a) See for example: Schiff, H. Justus Liebigs Ann. Chem. 1864, 131, 118. (b) Kuhn, R.; Schretzmann, H. Chem. Ber. 1957, 90, 557. (c) Stork, G.; Brizzolara, A.; Landesman, H.; Szmuszkovicz, J.; Terrell, R. J. Am. Chem. Soc. 1963, 85, 207.

(2) See for example: (a) Kyte, J. Mechanism in Protein Chemistry, $1^{\text {st }}$ ed.; Garland Pub.: New York, 1995. (b) Mukherjee, S.; Yang, J. W. , Hoffmann, S.; List, B. Chem. Rev. 2007, 107, 5471. (c) Erkkilä, A.; Majander, I.;Pihko, P. M. Chem. Rev. 2007, 107, 5416.

(3). (a) Kobayashi, S.; Ishitani, H. Chem. Rev. 1999, 99, 1069. (b) Córdova, A. Acc. Chem. Res. 2004, 37, 102. (c) Petasis, N. A.; Akritopoulou, I. Tetrahedron Lett. 1993, 34, 583. (d) Candeias, N. R.; Montalbano, F.; Cal, P. M. S. D.; Gois, P. M. P. Chem. Rev. 2010, 110, 6169. (e) Strecker, A. Justus Liebigs Annalen der Chemie 1850, 75, 27. (f) Wang, J.; Liu, X.; Feng, X. Chem. Rev. 2011, 111, 6947. (g) Pictet, A.; Spengler, T. Ber. Dtsch. Chem. Ges. 1911, 44, 2030. (h) Chrzanowska, M.; Rozwadowska, M. D. Chem. Rev. 2004, 104, 3341. (i) Knorr, L. Ber. Dtsch. Chem. Ges. 1884, 17, 2863. (j) Paal, C., Ber. Dtsch. Chem. Ges. 1884, 17, 2756. (k) Rodionov, W.M. J. Am. Chem. Soc. 1929, 51, 847. (I) Amarnath, V.; Anthony, D. C.; Amarnath, K.; Valentine, W. M.; Wetterau, L. A.; Graham, D. G. J. Org. Chem. 1991, 56, 6924. (m) Fields, E. K. J. Am. Chem. Soc. $1952,74,1528$.

(4) For selected examples of biocatalytic kinetic resolutions of amines, see: (a) Turner, N. J. Nat. Chem. Biol. 2009, 5, 567. (b)
Gotor-Fernandez, V.; Gotor, V. Curr. Opin. Drug Discovery Dev. 2009, 12, 784. (c) Lee, J. H.; Han, K.; Kim, M.-J.; Park, J. Eur. J. Org. Chem. 2010, 999 and references cited therein.

(5) For enzyme and metal complex cocatalyzed dynamic kinetic resolutions of amines, see: (a) Paetzold, J.; Bäckvall, J. E. J. Am. Chem. Soc. 2005, 127, 17620. (b) Park, E.-S.; Malik, M. S.; Dong, J.-Y.; Shin, J.-S. ChemCatChem 2013, 5, 1734. (c) Koszelewski, D.; Clay, D.; Rozzell, D.; Kroutil, W. Eur. J. Org. Chem. 2009, 2009, 2289.

(6) For leading examples of small molecule catalyzed kinetic resolutions of amines, see: (a) Arai, S.; Bellemin-Laponnaz, S.; Fu, G. C. Angew. Chem., Int. Ed. 2001, 40, 234 (b) Arp, F. O.; Fu, G. C. J. Am. Chem. Soc. 2006, 128, 14264 (c) Arnold, K.; Davies, B.; Herault, D.; Whiting, A. Angew. Chem., Int. Ed. 2008, 47, 2673. (d) Hou, X. L.; Zheng, B. H. Org. Lett. 2009, 11, 1789. (e) Reznichenko, A. L.; Hampel, F.; Hultzsch, K. C. Chem. Eur. J. 2009, 15, 12819. (f) De, C. K.; Klauber, E. G.; Seidel, D. J. Am. Chem. Soc. 2009, 131, 17060. (g) Klauber, E. G.; De, C. K.; Shah, T. K.; Seidel, D. J. Am. Chem. Soc. 2010, 132, 13624. (h) Klauber, E. G.; Mittal, N.; Shah, T. K.; Seidel, D. Org. Lett. 2011, 13, 2464. (i) Binanzer, M.; Hsieh, S. Y.; Bode, J. W. J. Am. Chem. Soc. 2011, 133, 19698. (j) Mittal, N.; Sun, D. X.; Seidel, D. Org. Lett. 2012, 14, 3084. (k) Min, C.; Mittal, N.; De, C. K.; Seidel, D. Chem. Commun. 2012, 48, 10853. (I) Hsieh, S.-Y.; Binanzer, M.; Kreituss, I.; Bode, J. W. Chem. Commun. 2012, 48, 8892. (m) Allen, S. E.; Hsieh, S.- Y.; Gutierrez, O.; Bode, J. W.; Kozlowski, M. C. J. Am. Chem. Soc. 2014, 136, 11783.(n) Mittal, N.; Lippert, K. M.; De, C. K.; Klauber, E. G.; Emge, T. J.; Schreiner, P. R.; Seidel, D., J. Am. Chem. Soc. 2015, 137, 5748. (7) For small molecule catalyzed kinetic resolutions of derivatives of amine, see: (a) Birman, V. B.; Jiang, H.; Li, X.; Guo, L.; Uffman, E. W. J. Am. Chem. Soc. 2006, 128, 6536. (b) Fowler, B. S.; Mikochik, P. J.; Miller, S. J. J. Am. Chem. Soc. 2010, 132, 2870. (c) Yang, X.; Bumbu, V. D.; Birman, V. B. Org. Lett. 2011, 13, 4755. (d) Yang, X.; Bumbu, V. D.; Liu, P.; Li, X.; Jiang, H.; Uffman, E. W.; Guo, L.; Zhang, W.; Jiang, X.; Houk, K. N.; Birman, V. B. J. Am. Chem. Soc. 2012, 134, 17605. (e) Xiao, K.-J.; Chu, L.; Chen, G.; Yu, J.-Q. J. Am. Chem. Soc. 2016, 138, 7796. (8) For non-catalytic kinetic resolutions of amines, see: (a) Krasnov, V. P.; Gruzdev, D. A.; Levit, G. L. Eur. J. Org. Chem. 2012, 1471. (b) Arseniyadis, S.; Valleix, A.; Wagner, A.; Mioskowski, C. Angew. Chem. Int. Ed. 2004, 43, 3314. (c) Karnik, A.V.; Kamath, S. S. Tetrahedron Asymm. 2008, $19,45$. (9) See the Supporting Information for details.

(10) For selected reviews on chiral phosphoric acid catalysis, see: (a) Akiyama, T. Chem. Rev. 2007, 107, 5744. (b) Terada M. Chem. Commun. 2008, 44, 4097. (c) Hoffmann, S.; Seayad, A. M.; List, B., Angew. Chem. Int. Ed. 2005, 117, 7590. (d) Adair, G.; Mukherjee, S.; List, B. Aldrichim. Acta 2008, 41, 31. (e) Terada, M. Synthesis 2010, 12, 1929. (f) Kampen, D.; Reisinger, C M.; List, B. Top. Curr. Chem. 2010, 291, 395. (g) Rueping, M.; Kuenkel, A.; Atodiresei, I. Chem. Soc. Rev. 2011, 40, 4539.

(11) For examples of introducing bulky $p$-substituents into TRIP, see: Cheng, X.; Goddard, R.; Buth, G.; List, B. Angew. Chem. Int. Ed. 2008, 47, 5079. (b) Cheon, C. H.; Yamamoto, H. J. Am. Chem. Soc. 2008, 130, 9246. (c) Horiguchi, K.; Yamamoto, E.; Saito, K.; Yamanaka, M.; Akiyama, T. Chem. Euro. J. 2016, 22, 8078. 
(12) Under our optimized conditions, the unreacted free amine is derivatized in situ with benzoic anhydride to ease isolation and characterization. To isolate the free amine, the crude reaction mixture is directly loaded onto a silica gel column, which is initially eluted with $30 \% \mathrm{Et}_{2} \mathrm{O}$-pentane $(\mathrm{v} / \mathrm{v})$ to obtain the enaminone product. Further elution with 0.1:1:9 (triethylamine: methanol: ethyl acetate) then provides the unreacted free amine. 
